\title{
ENTREVISTA: EDUCAÇÃO DO CAMPO E A PRODUÇÃO DE CONHECIMENTO: AVANÇOS, CONQUISTAS E DESAFIOS COM MÔNICA CASTAGNA MOLINA
}

\author{
Jeanne Mariel Brito de Moura Maciel ${ }^{1}$ \\ Rodrigo Simão Camacho²
}

Nos últimos 22 anos a Educação do Campo se consolidou como uma conquista da classe camponesa e, também, de fortalecimento de práticas pedagógicas vinculadas às dinâmicas de seu território. Nesse sentido, a entrevistada do primeiro número da Revista Interdisciplinar em Educação e Territorialidade (RIET), possui uma contribuição relevante nesse debate por ter participado ativamente da construção da Educação do Campo enquanto produção de conhecimento efetivada pelos sujeitos do campo.

Isso significa dizer que os sujeitos do campo são sujeitos de produção de conhecimento, de uma produção de saber significativa que não pode ser apagada do processo educativo. Na sua peculiaridade cultural e social, os camponeses - a partir de uma luta incessante junto aos movimentos sociais e auto-organização - reivindicam seu lugar no mundo e a primazia das narrativas de suas trajetórias. Portanto, para Molina, a própria produção do conhecimento na Educação do Campo não pode se desvincular do protagonismo dos sujeitos coletivos e da alternância. Isso porque, para ela, é esse entrelaçamento entre terra x trabalho x educação x identidade que vai produzir a própria dinâmica da produção de conhecimento e sedimentar as bases de uma educação camponesa libertadora.

Ao historicizar a gênese da Educação do Campo e a relação da produção de conhecimento juntamente com os sujeitos do campo, Mônica Molina aponta para a realização do I ENERA, que ocorreu em 1997, e para a I Conferência Nacional da Educação do Campo, em 1998, em que ficou evidente a ativa participação "dos sujeitos da Reforma Agrária, dos acampados e dos assentados".

Desde esse período, há muitas conquistas efetivadas pela Educação do Campo, dentre as quais ela destaca: as Licenciaturas em Educação do Campo, a efetivação de marcos legais que legitimam a especificidade da Educação do Campo e a organicidade da Educação do Campo e sua relação com os movimentos sociais. Contudo, há retrocessos em curso, aos quais nossa entrevistada assertivamente aponta como preocupantes e que dizem respeito às mudanças dos marcos legais da educação brasileira - com a efetivação da BNCC -, a tentativa de

\footnotetext{
1 Profa. Dra. da Universidade Federal da Grande Dourados (UFGD). Editora da Revista Interdisciplinar em Educação e Territorialidade (RIET).

2 Prof. Dr. da Universidade Federal da Grande Dourados (UFGD). Editor da Revista Interdisciplinar em Educação e Territorialidade (RIET).
} 
desmobilização do patrimônio político-pedagógico que foi acumulado pela Educação do Campo e o fechamento das escolas do campo nos municípios brasileiros.

São sobre esses aspectos da Educação do Campo - avanços, conquistas e desafios que a pesquisadora Mônica Molina nos leva a refletir.

Possui doutorado em Desenvolvimento Sustentável pela UnB (2003) e Pós-Doutorado em Educação pela UNICAMP (2013). Atualmente é professora associada da Universidade de Brasília (UnB), da Licenciatura em Educação do Campo, do Programa de Pós-Graduação em Educação e do Programa de Pós-Graduação em Meio Ambiente e Desenvolvimento Rural. Coordenou o PRONERA e o Programa Residência Agrária. Participou da I Pesquisa Nacional da Reforma Agrária (I PNERA) em 2003-2004, e Coordenou a II Pesquisa Nacional da Reforma Agrária (II PNERA), financiada pelo IPEA, em 2013-2015. Integra a pesquisa formação docente e a expansão do ensino superior, na coordenação do Sub 07: Educação Superior do Campo pelo Projeto Observatório da Educação do Campo da CAPES.

Desejamos uma boa e instigante leitura.

\section{Quais foram as principais conquistas da Educação do Campo ao longo desses 22 anos?}

Mônica Molina: Nesses 22 anos a Educação do Campo teve muitas e importantes conquistas. Conquistas no âmbito das políticas públicas, conquistas no âmbito do estabelecimento de Marcos legais, conquistas no âmbito da produção de conhecimento científico e especialmente da articulação na consolidação de um determinado patrimônio político-pedagógico materializado pelas suas práticas desenvolvidas no país inteiro.

Então, sem sombra de dúvidas, a Educação do Campo nesses 22 anos se territorializou em todo o nosso país e conseguiu, a partir das concepções educativas que ela defende, materializar práticas, articular práticas novas e articular práticas que já existiam, mas que passaram a se reconhecer nessa concepção formativa nos diferentes níveis da educação brasileira: na educação básica, na educação superior e, também, na pós-graduação. Então, nesses 22 anos a Educação do Campo se territorializou em todo o nosso país nas diferentes unidades da federação e, também, nos diferentes níveis de ensino. Essa intensidade se relaciona a diversos fatores, dentre os quais, podemos destacar um maior ou menor protagonismo dos movimentos sociais, a existência de governos mais sensíveis e progressistas, uma maior ou menor aproximação com universidades e docentes parceiros. Esse conjunto variado de fatores é o que faz com que se tenha avanços maiores ou menores, tanto na educação básica quanto na educação superior.

Essa diversidade de experiências é protagonizada pelos sujeitos coletivos do campo, sejam os sujeitos organizados nas Escolas Famílias Agrícolas, nas Casas Familiares Rurais, nos Sindicatos dos Trabalhadores através das federações dos trabalhadores rurais e da CONTAG, da sua associação nacional ou através do Movimento de Trabalhadores rurais Sem Terra - sem dúvida nenhuma um dos principais protagonistas de todo esse processo de construção da Educação do Campo com sua enorme experiência das Escolas Itinerantes, das Escolas dos Assentamentos e das escolas de formação do próprio movimento. Enfim, através de uma enorme e ampliada rede de formação e de ação educativa no Brasil que o movimento dos Sem- 
Terra tem, não é? Mas, também, que além dessas práticas têm as políticas públicas que essas práticas materializam. Assim, a primeira política pública de Educação do Campo que vai surgir é o próprio PRONERA - Programa Nacional de Educação na Reforma Agrária, que nasce do ENERA - do primeiro Encontro Nacional dos Educadores e Educadoras da Reforma Agrária, que inclusive á está bastante escrito e registrado em muitas publicações da Educação do Campo no nosso país.

Então, além do PRONERA, há o programa Saberes da Terra, outra política pública relevante. Depois, temos o Residência Agrária - uma política fundamental na área do apoio e organização da produção para a classe trabalhadora -, com os cursos de especialização do Residência Agrária em todo país. O Residência Agrária teve um primeiro edital e, depois, um segundo edital com mais de 37 universidades. Finalmente, há as próprias licenciaturas em Educação do Campo, que também são uma política pública importante.

Entendo hoje que as licenciaturas do campo têm um papel fundamental na consolidação das compreensões defendidas pela Educação do Campo porque elas se territorializaram em todo o nosso país. Atualmente, temos 46 licenciaturas em Educação do Campo em todo o país, com mais de 600 educadores nessas licenciaturas e cerca de 7000 educandos. Há, também, os vários programas de pós-graduação específicos para a Educação do Campo, como um mestrado territorial na UNESP que é uma experiência relevante no nosso país, também linhas de pesquisa em Educação do Campo em várias universidades, como na própria UNB, com mestrado e doutorado. Além disso, outra conquista da Educação do Campo foi a criação do mestrado em educação profissional do campo na UFRB. Essas conquistas são todas muito importantes e se materializam de forma significativa por meio da produção do conhecimento que tem sido gerado pelos camponeses.

Isso é relevante porque durante muito tempo o apagamento da ciência campesinato foi parte do apagamento do campesinato na história, como também nos lembra aquela coleção do Campesinato Brasileiro produzida pelo NEAD com vários pesquisadores da Unesp juntamente com o coletivo do CPDA no Rio de Janeiro. Portanto, esse avanço na produção do conhecimento é significativo na medida em que se torna um patrimônio da Educação do Campo, e que essa produção do conhecimento tem se materializado exatamente não só por pesquisadores de fora, por pesquisadores das universidades, mas principalmente pelos próprios sujeitos camponeses que a partir dessas lutas e da conquista dessas políticas públicas, se inserem na educação superior e se transformam em pesquisadores da sua própria realidade, podendo narrar suas histórias dos acampamentos, dos assentamentos, das cooperativas, dos desafios da organização da produção a partir da agroecologia enfim, da transformação dos seus territórios. Esse é um grande diferencial da Educação do Campo enquanto protagonista da produção do conhecimento, tendo como ação central os próprios sujeitos camponeses. Digo isso fundamentada em pesquisas científicas que viemos fazendo nos últimos anos.

Ao realizar uma análise dos trabalhos de teses e dissertações produzidas pelo PRONERA sobre as licenciaturas em Educação do Campo, constatamos nessas produções um número extremamente relevante, significativo dos próprios sujeitos camponeses que participaram nesses processos formativos tanto dos cursos do PRONERA, quanto das licenciaturas em Educação do Campo. Isso significa que eles estão produzindo conhecimento 
científico, que estão produzindo dissertações e teses sobre os seus territórios a partir dessa formação acadêmica que esses sujeitos alcançaram. Eu penso uma das grandes conquistas é que há uma mudança epistemológica na produção desse conhecimento. Veja, esses sujeitos têm sido capazes de conseguir produzir esse conhecimento de uma maneira nova e transformadora ao dialogar com os conhecimentos científicos que acessam na universidade, mas sem hierarquizá-los, sem desprezar e minimizar todos os conhecimentos que esses sujeitos já têm da produção material da vida que fazem seus territórios. E isso tudo a partir do diálogo com os saberes ancestrais e do diálogo com práticas enraizadas em suas comunidades rurais de origem.

Nessa pesquisa que realizamos, vale destacar que várias dessas teses e dissertações analisadas tanto do PRONERA quanto da Licenciatura em Educação do Campo, tiveram como foco a especificidade dos processos de produção do conhecimento científico feito por esses sujeitos, exatamente analisando essa relação do conhecimento científico com os saberes populares.

Essa conquista deve ser valorizada, e foi isso que fizemos no seminário dos 20 anos da Educação do Campo, que ocorreu no ano de 2018, na UNB. Nós refletimos que hoje a Educação do Campo não é mais só Educação do Campo, é do campo, da floresta, das águas e das geazeiras, dos cerratenses, é das comunidades de fundo de pasto, dos quilombolas, enfim, de uma imensa diversidade de sujeitos que ocupam a Educação do Campo e que hoje estão nas Licenciaturas em Educação do Campo.

Essa diversidade de sujeitos presentes na licenciatura em Educação do Campo faz com que a própria universidade ao acompanhar o denominado "tempo comunidade", que ocorre nessas licenciaturas, vá descobrindo e conhecendo as especificidades da produção material da vida desses diferentes sujeitos coletivos e passe a ressignificar, dessa forma, os seus processos de produção de conhecimento. Portanto, reafirmo que uma das grandes conquistas da Educação do Campo é também ajudar a própria educação superior, e os docentes que atuam na educação superior das diferentes áreas do conhecimento, a ressignificarem os olhares que possuem para esses territórios.

\section{Há diferenças nessas conquistas quando pensamos a Educação do Campo em nível Básico e Superior?}

Mônica Molina: Sim, penso que há diferenças quando pensamos nas conquistas da Educação do Campo no âmbito da educação básica e da educação superior, e essas diferenças dizem respeito a vários fatores, entre eles a própria diferença do tamanho dessas redes: da rede de educação básica no nosso país, da rede da educação superior, da distribuição espacial dessas redes e dos sujeitos que a frequentam.

Penso que a Educação do Campo avançou bem mais na educação do superior do que na educação básica. Poderíamos dizer que nós temos hoje, de uma maneira consolidada, experiências relevantes no âmbito da educação superior em nosso país e que envolve um número significativo de universidades, de centros de pesquisa, de docentes, de educadores e de educandos. Temos também experiências relevantes na educação básica no nosso país, mas em número bem menor se comparado ao tamanho da rede da educação básica. Quer dizer que não 
temos experiências consolidadas, temos, porém, em vários estados experiências fundamentais de transformação da forma escolar na educação básica a partir dos princípios da Educação do Campo. De certa forma, há experiências riquíssimas no Pará, em Pernambuco, no Ceará, no Mato Grosso, no Paraná e no Rio Grande do Sul. Enfim, em diferentes unidades federadas temos importantes experiências no âmbito da educação básica na Educação do Campo, temos muito mais escolas hoje no território rural que nós poderíamos dizer que elas continuam sendo escolas rurais do que escolas nos territórios rurais que foram transformadas, ainda que não na sua totalidade, mas que poderíamos chamar essas unidades escolares de escolas do campo, ou seja, escolas que têm alguns -pelo menos alguns- daqueles pressupostos que configuram essa categoria forjada na própria luta da Educação do Campo e definido no dicionário da Educação do Campo, que são as escolas do campo, escolas que têm um protagonismo dos movimentos sociais camponeses, escolas em que os conteúdos são trabalhados a partir de uma profunda vinculação com a realidade, com a ligação da escola com a vida, na qual as relações sociais são transformadas nesse espaço, onde há uma vinculação com a luta pela Terra com a produção da agroecologia e da soberania alimentar, enfim, em que há toda uma dimensão vinculada à superação, ao papel da escola nas contribuições para a superação da sociedade capitalista.

Escolas do campo há muitas, mas, sem dúvida, há mais escolas rurais do que escolas do campo no nosso país. Esse é, ao mesmo tempo, uma constatação e um grande desafio. Precisamos nos aproximar muito mais das escolas básicas do campo, precisamos avançar no trabalho geral com a formação de educadores e com os educandos como sujeitos camponeses que estão nessas escolas em todo o território rural do nosso país.

\section{Como o processo de formação de educadores do campo pode auxiliar na transformação social?}

Mônica Molina: O processo de formação de educadores pode auxiliar na transformação social na medida que ele tem um papel fundamental na constituição da visão de mundo que os sujeitos têm. Veja, essa é uma das principais tarefas dos educadores, contribuir com a construção de uma determinada visão de mundo que os sujeitos que passam pela escola vão ter. Então, os educadores podem contribuir para formar sujeitos que sejam capazes de compreender a totalidade dos processos sociais, de desvelar a aparência dos fenômenos e chegar a sua essência, e conseguir realizar essa distinção entre aparência e essência. Os educadores têm o papel de formar sujeitos que sejam capazes de olhar para a realidade e entender que a realidade não é exatamente tal qual ela se aparenta para os sujeitos, mas que tem as múltiplas determinações dessa aparência da realidade que fazem com que ela se apresenta tal qual nós a vemos, e que sejam capazes de chegar à essência dessa realidade. Entender essas contradições que estão por trás das aparências dos fenômenos e formar sujeitos que tenham capacidade não só de compreender a realidade, de enxergar essas contradições da realidade, mas, principalmente, de agir para transformar essa realidade, de agir nessa realidade no sentido de desencadear processos que promovam sua transformação, essa é a sua função. Por isso que os educadores têm um papel tão importante de contribuir com a transformação social, visto que os educadores podem formar sujeitos que tenham esta capacidade de leitura crítica da realidade e de atuação nessa realidade no sentido de sua transformação. É por isso que na Educação do Campo 
trabalhamos tanto com Pistrak, pois queremos despertar a ideia de que a escola tem um papel de formar lutadores e construtores do futuro, ao invés de a escola formar - como nos diz o professor Luiz Carlos de Freitas - um "rebanho disciplinado". Portanto, ao invés de a escola formar sujeitos cuja inspiração vem do exército, da igreja - é por isso que ele diz ser um "rebanho disciplinado" -, pacífico, que não pensam e que só cumprem ordens, pretendemos formar sujeitos que lutem e se organizem e que sejam construtores do futuro - como diria Pistrak.

Nesse sentido, os educadores podem, nos tempos e nos espaços educativos que têm com os seus educandos, desenvolver processos que promovam a autonomia dos sujeitos, e formar educadores que possam pensar criticamente por si só - e não ser um rebanho disciplinado- e, assim, formar sujeitos que pensem e que sejam capazes de ação, que sejam capazes de ação coletiva e promover processos de auto-organização. Então, entra aí uma outra categoria fundamental da própria Educação do Campo, a auto-organização dos educandos, é por isso que o papel dos educadores é tão importante.

Então uma outra categoria muito importante do porquê a formação de educadores pode contribuir com a transformação social, é se ela for capaz de formar sujeitos críticos, se for capaz de formar sujeitos de ação, se for capaz de formar sujeitos que se auto-organizem e trabalhem coletivamente. Onde se ancora toda essa concepção de formação de educadores que podem contribuir com a transformação social? Exatamente na ideia da epistemologia da práxis. Formar sujeitos capazes de práxis, que sejam capazes de não só pensar criticamente sobre sua realidade, de agir sobre ela, mas de transformá-la. Em uma palavra: sujeitos que sejam capazes de voltar para a teoria refazendo a teoria, ressignificando a teoria. Então, formar sujeitos que exatamente tenham as condições necessárias, tenham desenvolvidas as habilidades para o exercício da práxis, para viver aquilo que Gramsci propõe na filosofia da práxis, visto que, na verdade, Gramsci segue o pensamento de Marx que é quem idealiza essa ideia da filosofia da práxis e depois Gramsci dá sequência à essa concepção. Por isso, na Educação do Campo, trabalhamos na perspectiva da formação de educadores a partir da ideia da epistemologia da práxis, então o processo de formação de educadores pode, e deve, auxiliar na transformação social na medida em que forma sujeitos que sejam capazes de contribuir com a transformação social.

\section{Porque a Educação do Campo pode ser considerada como uma práxis contra- hegemônica?}

Mônica Molina: Porque a hegemonia na nossa sociedade é a hegemonia do capital, e a Educação do Campo tem como principal fundamento a compreensão de que é necessário superar a lógica da sociedade capitalista. A lógica da sociedade capitalista é uma lógica que destrói a humanidade, que destrói a vida e os seres humanos, e a Educação do Campo tem como sua essência a defesa da vida, a defesa da valorização da vida de todos os sujeitos, da igualdade e da justiça social. E é impossível a igualdade e a justiça social na sociedade capitalista, portanto, ela é contra-hegemônica porque ela parte dessa compreensão, de que é necessário superar a lógica da sociedade capitalista que é fundada em duas grandes leis: a) da exploração do homem-pelo-homem; b) da exploração da natureza. Assim, a Educação do Campo é contrahegemônica porque visa construir práticas educativas, práticas formativas que busquem um 
outro ethos societário, que busque uma sociedade não da exploração do homem-pelo-homem, não da exploração insana da natureza, mas uma lógica de solidariedade, de cuidado, de respeito da vida humana, de distribuição de produção e distribuição igualitária da riqueza gerada pela classe trabalhadora. Que busque superar a essência do capitalismo que é a produção de maisvalia, que é a exploração do sobretrabalho. Então, a Educação do Campo é contra-hegemônica porque compreende que é necessário construir uma sociedade de trabalhadores onde todos trabalham, e não onde uns vivam do trabalho dos outros. Ao afirmarmos e defendermos o trabalho como princípio educativo, ao trabalharmos na Educação do Campo com a ideia da necessidade imperiosa da emancipação humana, portanto, não só da emancipação política, nos colocamos exatamente no polo da contra-hegemonia, tentando superar os fundamentos que estruturam a lógica da sociedade capitalista.

\section{Podemos considerar a Educação do Campo como um novo paradigma educacional? Por quê?}

Mônica Molina: A grande novidade da Educação do Campo é que ela coloca em cena sujeitos que nunca haviam protagonizados o cenário educacional brasileiros, os próprios camponeses, os trabalhadores que vivem e que garantem a produção material da vida a partir do território rural de nosso País. Essa é sua maior novidade histórica, mas ela não inaugura um paradigma. Por quê? Porque ela é herdeira e se coloca no leito das pedagogias emancipatórias, das pedagogias que buscam a emancipação humana, a pedagogia socialista, a pedagogia do oprimido. A Educação do Campo é herdeira de várias concepções pedagógicas e o seu grande diferencial é exatamente trazer à cena pública brasileira os camponeses, os trabalhadores com o seu protagonismo e assim como essas outras pedagogias sempre se pautou por perguntas fundamentais que são: que sociedade queremos? Que ser humano queremos formar para construir essa sociedade que queremos? E que concepções de educação podemos materializar para formar esse ser humano para essa sociedade que queremos? E a isso ela responde: queremos formar uma sociedade que supere a sociedade capitalista, uma sociedade socialista, uma sociedade de trabalhadores e, portanto, precisamos de uma concepção e de uma prática educativa que nos ensine a formar sujeitos, a formar trabalhadores, a formar a república do trabalho. Então, uma sociedade que compreenda a centralidade do trabalho para a manutenção da vida humana. Somos seres de necessidades e qual a própria essência da categoria trabalho: trabalho é a ação do homem sobre a natureza para suprir as suas próprias necessidades e não vida sem trabalho. Então, somos seres que necessitamos nos alimentar, morar, nos educar, produzir cultura, enfim, e para suprir as nossas necessidades precisamos do trabalho e é nesse sentido que queremos formar uma sociedade de trabalhadores, uma sociedade onde sejamos todos capazes de reorganizar o nosso tempo de trabalho para suprir as necessidades de todos os seres humanos. Isso que está em questão. Então, a Educação do Campo considera e entende que, exatamente pela sua compreensão da humanidade, pela sua compreensão do direito humano, é necessário que o homem tenha condições, a partir de seu trabalho e da sua compreensão da própria ideia de totalidade, de suprir as necessidades com a organização das forças produtivas que já temos condições de fazer hoje, de suprir as necessidades de todos os 
seres humanos. Então, nesse sentido a Educação do Campo é herdeira e se coloca junto às pedagogias socialistas.

\section{Como podemos avaliar quais são os desafios para a Educação do Campo atualmente?}

Mônica Molina: O primeiro grande desafio e a tarefa de todos os militantes, pesquisadores da Educação do Campo é lutar em defesa da própria democracia. Enfrentamos um momento complexo do avanço muito grande de forças extremamente perigosas na sociedade brasileira, dentro do Estado brasileiro, forças que desprezam a democracia, que desprezam os valores humanos, que desprezam a vida. Temos vistos crescer nesses últimos dois anos, a necropolítica, a política do extermínio, a política da eliminação dos camponeses, a política da morte, a política que nega a diversidade social, a política que mata deliberadamente. Então, penso que uma grande tarefa que temos, todos nós, é debatermos à exaustão com o conjunto da sociedade brasileira, esse imenso retrocesso que temos vivenciado, essa negação dos direitos humanos, essa negação dos direitos da própria natureza. Então, esse avanço avassalador do capital sobre os territórios camponeses e essa destruição da natureza que temos enfrentado nesses últimos dois anos nos coloca esse imenso desafio: pensarmos a partir da própria totalidade social, da complexidade, do que é esse momento histórico que enfrentamos. O primeiro desafio da Educação do Campo é entender que está em risco a própria democracia. Assim, é importante recuperar uma ideia central de Marilena Chauí, quando ela nos ensina que "a democracia é o único regime político onde o conflito é legítimo". A essência da democracia é a ideia do direito a ter direitos. A Educação do Campo se estruturou nesses últimos 22 anos no direito a ter direitos. O fato dos camponeses se colocarem em luta organizados pelo direito a terra, pelo direito a educação está fundamentado nessa ideia. Esses direitos estão estabelecidos, mas não estão materializados. E a Marilena Chauí nos alerta: quando os direitos estão positivados, mas não estão concretizados na democracia, tem se o direito e o dever de lutar por eles. É exatamente essa ideia do direito a ter direitos que fez com que a Educação do Campo avançasse tanto. Foi essa concepção que possibilitou os sujeitos camponeses, organizados em luta de disputarem os fundos públicos do Estado para conquistarem políticas públicas específicas para garantir o direito à educação dos camponeses. Eles já têm direito à educação porque o direito à educação é um direito humano, independente do lugar onde se vive, os sujeitos humanos têm direito à educação; os camponeses em luta buscam o direito à educação exatamente fundado nessa ideia em que os direitos estão positivados mas não materializados, então, o fazem através daquilo que eu colocava anteriormente: a democracia é o único regime político onde o conflito é legítimo. Por isso, a luta pela terra através das ocupações, através dos processos de mobilização, a luta pela conquista de políticas públicas especialmente da educação, nesse sentido da compreensão de que a educação é fundamental para o desenvolvimento dos territórios e onde o campesinato se coloca, é que dão materialidade a essa compreensão da Educação do Campo. Desse modo, retomando a ideia da indissociabilidade da Educação do Campo a partir do que a gente chama de tríade estruturante: campo, política pública e educação, de uma maneira extremamente articulada e pensar a relação dos conflitos que existem entre essas três dimensões, e as contradições existentes em cada um desses três polos é que dão a materialidade da origem da Educação do Campo. As contradições na disputa de projetos de campo, as 
contradições na educação e as contradições na concepção de quem são os protagonistas das políticas públicas, é que materializam essa compreensão da Educação do Campo. Assim, no momento, seu maior desafio seria manter a democracia em toda a sociedade brasileira diante de um governo extremamente autoritário e que nega a democracia como um valor.

O segundo desafio é a luta em defesa da própria educação pública exatamente associada à ideia anterior da perda dos valores democráticos, do avanço desses forças conservadoras, privatistas e negacionistas, a gente vive nesse momento um grande ataque à educação pública, como nos alerta o professor Luis Carlos de Freitas, de que os reformadores empresariais da educação estão avançando com muita força sobre o estado brasileiro, disputando os fundos públicos e transformando a educação em mercadoria, tirando a educação do âmbito público e do Estado, e colocando a educação no privado, privatizando-a e transformando-a em mercadoria. A gente tem visto isso em um conjunto grande de políticas educacionais, na formação de educadores, na produção de materiais didáticos, na política de formação inicial e continuada, enfim, há um movimento orquestrado daqueles que entendem a importância da educação nessa perspectiva própria do capitalismo. Nesse sentido, a educação tem uma função sócio metabólica do capital, sendo transformada e concebida a partir de seus interesses e, nessa compreensão, há a apropriação dos fundos públicos que eram direcionados à educação pública. Esse é um grande desafio e tarefa da Educação do Campo. Se no período anterior foi possível avançarmos em defesa da especificidade da Educação do Campo, agora a nossa tarefa é lutar pela própria garantia da existência da educação pública. Não há Educação do Campo sem educação pública e nesse momento a educação pública está em risco em nosso país e em risco acelerado; e esse risco se dá, especificamente, por esse avanço das forças privatistas sobre o estado brasileiro, conseguindo articular um conjunto grande de políticas e transformando o acesso e a permanência na educação. Por isso devemos estar alertas para manter a educação como direito e manter a educação no âmbito do público, sendo esse o grande desafio para que a Educação do Campo possa continuar existindo. Não podemos deixar envolver por esse conjunto de concepções e paradigmas que reduzem profundamente o direito à educação, com essas pedagogias que haviam sido enterradas há mais de 40 anos e que retornam com muita força, me referindo nesse caso à pedagogia das competências e a outras tantas questões que estão sendo colocadas nesse momento histórico.

O terceiro desafio, junto com a luta em defesa da democracia e em defesa da educação pública, é nos articularmos com os outros setores e com as outras organizações em defesa da educação do nosso país, para barrarmos os imensos retrocessos que estão sendo impostos à classe trabalhadora a partir da mudança dos marcos legais da educação brasileira. Estão em curso, de uma forma extremamente acelerada e articulada, as mudanças das principais políticas educacionais do nosso país: a política da formação de educadores, da produção de material didáticos, de gestão escolar, dos conteúdos que são ensinados, enfim, de uma maneira muito forte esses reformadores empresariais da educação estão transformando os marcos legais que havíamos construído com muita luta na história da educação brasileira. Um dos principais exemplos que podemos dar, é no âmbito da política nacional da formação de educadores. Nós vimos nesse período recente a substituição do grande marco que tínhamos para a formação de educadores que eram as diretrizes curriculares nacionais para a formação dos professores da educação básica através da resolução 2/2015 que foi construída com muita participação da 
sociedade civil - com amplo diálogo com as organizações de pesquisa como a ANPED, como a ANFOPE, CNTE- e a sua substituição de maneira absolutamente abrupta e desrespeitosa pela resolução 2/2019, sem diálogo com as comunidades científicas e com os pesquisadores da área da educação. Esse é um grande desafio que temos na Educação do Campo, nos articularmos com outros setores da educação brasileira, da educação progressista, e trabalharmos no sentido da revogação dessa resolução 2/2019. Por quê? Porque esta resolução impõe imenso retrocesso à política nacional de formação de educadores no nosso país, pois retoma princípios e práticas extremamente conservadoras, enterrando toda uma construção teórica que foi construída coletivamente e que, em grande medida, estava materializada na resolução 2/2015. Portanto, falamos aqui de uma concepção de formação de educador que a resolução 2/2015 trazia, e que diz respeito a concepção da relação entre teoria e prática, a articulação indissociável da formação inicial e continuada, da autonomia do trabalho docente e, também, da possibilidade da necessidade da articulação dos conteúdos curriculares com os diferentes territórios e sujeitos envolvidos no processo educativo, visto que tudo isso é enterrado nessa resolução recente de 2/2019 que acabou por revogar a resolução 2/2015, retomando um debate que já havíamos superado na teoria pedagógica no nosso país a partir do debate da "pedagogia das competências". Isso veio com muita força e é extremamente grave porque é articulado não só à política de formação de educadores, mas também articulado a outras políticas educacionais: a política de material didático e a política de formação continuada. Enfim, são paradigmas educacionais extremamente conservadores que estão se colocando novamente no cenário da educação brasileira. Daí precisarmos compreender que os elementos que estão presentes nessa resolução de 2/2019 estão articulados intrinsecamente à BNCC e à Base Nacional de Formação. A articulação desses elementos coloca a escola e a educação a partir dos princípios embutidos nessa legislação a serviço do capital, e busca eliminar os espaços da formação política, da formação emancipatória e da formação questionadora, e coloca no lugar uma proposta de formação docente limitadora. Coloca, pois, como princípio e como diretriz fundamental a epistemologia da prática, o saber-fazer e uma amarra na prática educativa, limitando cada vez mais a partir de uma articulação intensa com a BNCC sobre o que deve ser ensinado nas escolas e tira do docente sua função essencial, que é a capacidade da formação da crítica, do pensamento autônomo e da capacidade de leitura e avaliação da realidade. Esse é um grande desafio que a Educação do Campo enfrenta nesse momento, que é barrar o retrocesso que está sendo imposto a partir dos marcos legais. Mas a Educação do Campo não pode fazer isso sozinha. É preciso que, cada vez mais, nós pesquisadores, e militantes da Educação do Campo, estejamos articulados com todas as outras instituições que lutam pela educação no nosso país para enfrentarmos esse acelerado processo de privatização da educação brasileira, junto om a ANFOPE, com a ANPED, com o CNTE, com a ANPAE, e com a própria ANDIFES e outras organizações que lutam pela educação popular.

Um quarto desafio que também é importante para a Educação do Campo nesse momento, é conseguir colocar todo esse imenso patrimônio político-pedagógico que foi acumulado pela Educação do Campo nesses 22 anos uma luta contra todos esses retrocessos que vimos enfrentando. Então, penso que um desafio nesse momento é compor estratégias para mobilizarmos todos os educadores, educandos e envolvidos nas Licenciaturas em Educação do Campo, nessas lutas. Veja, nós temos hoje cerca de 7 mil educandos nas Licenciaturas em 
Educação do Campo, e isso é uma força material significativa juntamente com os 600 educadores, vários mestrandos e doutorandos pesquisando sobre o tema. Portanto, é preciso que nós ampliemos essa capacidade de articulação e de mobilização de luta desses sujeitos. Acredito que um passo importante tem sido dado pelo FONEC (Fórum Nacional de Educação do Campo), que nesse ano de 2020 avançou muito na sua capacidade de organização e na sua organicidade interna, criando as várias frentes de mobilização do Fórum Nacional de Educação do Campo em defesa das escolas do campo e das licenciaturas, e em defesa do PRONERA. Enfim, essas frentes criadas no FONEC são espaços importantes de luta e de auto-organização, e entendo que um dos desafios da Educação do Campo é avançar na organicidade interna, na nossa mobilização e no envolvimento dos estudantes da Educação do Campo e dos egressos da Educação do Campo, seja nos cursos do PRONERA, seja nos cursos de Pedagogia da Terra, em defesa da democracia, em defesa da educação pública numa concepção crítica e emancipatória de educação.

O quinto e último desafio da Educação do Campo nesse momento é retomar, especialmente nos cursos das Licenciaturas em Educação do Campo, a vinculação e o protagonismos dos movimentos sociais nesses espaços formativos. Isso porque, ao mesmo tempo que nós avançamos muito construindo toda uma institucionalização da Educação do Campo, avançando para termos hoje 46 cursos permanentes de licenciatura com um número significativo de docentes concursados na educação superior para tal, nós também, contraditoriamente, vivenciamos um afastamento dos movimentos sociais do campo desses espaços, e isso é fundamental porque é a essência da Educação do Campo. Portanto, acredito que precisamos, como um desafio coletivo, avançar na reconstrução dessa organicidade, desse vínculo que deve ser permanente, dos movimentos sociais do campo com esses espaços formativos. E isso nos coloca um outro desafio fundamental para a Educação do Campo, junto com esses movimentos, que é a luta contra o fechamento das escolas do campo, pela manutenção das escolas existentes e pela ampliação das escolas existentes. A gente sabe muito bem que um dos primeiros passos para desterritorializar uma comunidade é fechar a escola, e para o latifúndio e para o agronegócio isso é uma condição fundamental, visto que eles precisam para a implementação dessa lógica de organizar a agricultura enquanto um negócio, portanto, como produção de mercadoria e de mais-valia, eles precisam de um campo sem sujeito, de uma ruralidade de espaços vazios, e fechar as escolas e desterritorializar os sujeitos é a condição sine qua non para a implementação dessa lógica de acumulação do capital no campo. Nisso se coloca um outro desafio que temos junto com a reaproximação dos movimentos sociais do campo nesses espaços formativos, que é a luta contra o fechamento das escolas do campo, como muito bem tem dito aquela campanha do MST do Paraná "fechar as escolas é crime" e, também, a ideia de que "a escola é vida na comunidade". Esse é um outro desafio muito importante da Educação do Campo nesse momento. 